\title{
Transcreation Strategies of Male-Related Traits from English Online Fragrance Labels into Chinese: From a Cultural Perspective
}

Li Zhu, Lay Hoon Ang, Sabariah Binti Md Rashid, Nor Shahila Binti Mansor

To Link this Article: http://dx.doi.org/10.6007/IJARBSS/v11-i4/9839

DOI:10.6007/IJARBSS/v11-i4/9839

Received: 03 February 2021, Revised: 01 March 2021, Accepted: 26 March 2021

Published Online: 29 April 2021

In-Text Citation: (Zhu et al., 2021)

To Cite this Article: Zhu, L., Ang, L. H., Rashid, S. B. M., \& Mansor, N. S. B. (2021). Transcreation Strategies of Male-Related Traits from English Online Fragrance Labels into Chinese: From a Cultural Perspective. International Journal of Academic Research in Business and Social Sciences, 11(4), 1408-1422.

Copyright: @ 2021 The Author(s)

Published by Human Resource Management Academic Research Society (www.hrmars.com)

This article is published under the Creative Commons Attribution (CC BY 4.0) license. Anyone may reproduce, distribute, translate and create derivative works of this article (for both commercial and non-commercial purposes), subject to full attribution to the original publication and authors. The full terms of this license may be seen at: http://creativecommons.org/licences/by/4.0/legalcode

Vol. 11, No. 4, 2021, Pg. 1408 - 1422

Full Terms \& Conditions of access and use can be found at http://hrmars.com/index.php/pages/detail/publication-ethics 


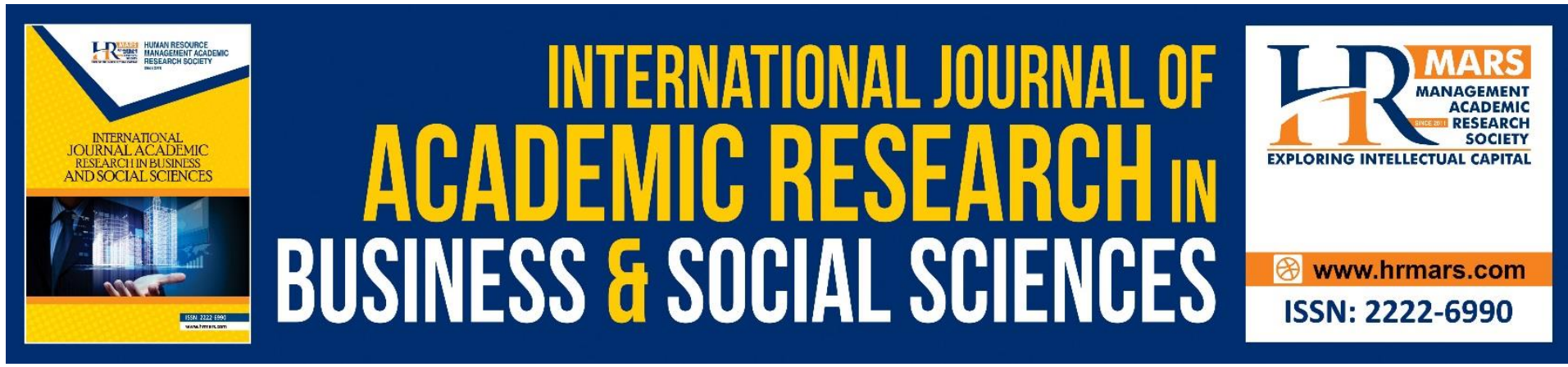

\title{
Transcreation Strategies of Male-Related Traits from English Online Fragrance Labels into Chinese: From a Cultural Perspective
}

\author{
Li Zhu' ${ }^{1,2}$, Lay Hoon Ang ${ }^{1}$, Sabariah Binti Md Rashid ${ }^{1}$, Nor \\ Shahila Binti Mansor ${ }^{1}$ \\ ${ }^{1}$ Faculty of Modern Languages and Communication, Universiti Putra Malaysia, 43400, \\ Selangor, Malaysia, ${ }^{2}$ Department of Foreign Languages, Baise University, 533000, Baise, \\ China. \\ Email: hlang@upm.edu.my
}

\begin{abstract}
In recent years, transcreation has been a buzzword in the translation industry and academia. It is defined as a combination of translation and new content creation, with translation used in its traditional sense. Although transcreation strategies have been explored, few studies have addressed whether translation or new content creation predominates in transcreation strategies and the underlying cultural reasons. This study examines the transcreation strategies involved in the Chinese translations of male stereotypes in English online fragrance labels. More specifically, as transcreation strategies can be divided into minimal and marked interventional strategies, this paper examined the cultural reasons underlying marked interventional strategies drawing on the Hofstede model. It adopts a descriptive and interpretive qualitative research method. A non-probability purposive sampling method is used to collect data. Findings illustrate that marked interventional strategies, including addition, substitution and omission, predominate transcreation strategies. Whereas minimal change including direct translation is less. The unveiled cultural reasons suggest the differences of male stereotypes in advertising between China and the US, thus contributing to the research on East-West comparison of male stereotypes. Meanwhile, it will provide implications for translators to deal with male stereotypes in advertising.
\end{abstract}

Keywords: Translation, Transcreation Strategy, Male Stereotype, Online Fragrance Label, Culture

\section{Introduction}

In recent years, western luxury beauty products have become immensely popular in Chinese markets. To date, almost $80 \%$ of western luxury brands have gone into Chinese digital markets (Rovai, 2018). The pandemic lockdowns of COVID-19 have accelerated the move to online beauty. Accessible luxury fragrance, for instance, has become a new way for millennial men in China to demonstrate their individualism (Luo, 2019). To appeal to these male customers, advertisers usually allude to the personality traits (e.g., 'confident', 'manly') and physical characteristics (e.g., 'strong', 'muscular') of the intended consumers to describe the male 
fragrance in their online labels. Deaux and Lewis's (1984) multicomponent structure assert that personality traits and physical characteristics are two components of male stereotypes. They identify four components indicating male stereotypes, with the other two components as role behaviours (e.g., being a leader) and occupational status (e.g., truck driver). We summarise personality traits and physical characteristics in this context as male-related traits. In this sense, male-related traits refer to two components of male stereotypes proposed by Deaux and Lewis (1984), namely personality traits and physical characteristics, as reflected by words and phrases. Thus, male-related traits could be used as an instrument to measure male stereotypes in online fragrance labels.

Male stereotypes in advertising have been studied by various scholars (Del Saz-Rubio, 2019; Pitaloka \& Suryandaru, 2020; Waling et al., 2018, among others). Given the increasing market demand for translating online fragrance labels from English into Chinese and the importance of male stereotypes for advertisers, the interplay between translation and male stereotypes in online fragrance labels is worthy of inquiry. Research on the interplay between translation and male stereotypes in advertising has been conducted by scholars such as Nardi (2011) and Chulanova and Shevchenko (2017). When it comes to advertising translation, transcreation is a crucial term widely recognised in both the translation industry and academia. As transcreation strategy has been proposed by scholars such as D. Pedersen (2016), the present paper also use the term 'transcreation strategy' to describe the translation strategy used in advertising translation.

Specifically, this study aims to shed light on the transcreation strategies used when rendering male-related traits in online fragrance labels for Chinese consumers. To do so, it identifies male-related traits in the source text (ST) and target text (TT). This analysis focuses on fragrance labels collected in American and Chinese websites to explore the cultural impacts on rendering male-related traits in international advertising. The research finding described herein indicates the differences of male stereotypes in advertising between China and the US, thus contributing to East-West comparison of male stereotypes. It also expands our understanding on the cultural factors considered when translating male-related traits in adverts for different markets. For instance, the male-related traits depicted in the Chinese market may be influenced by the notion of China's Confucius.

\section{Literature Review}

Male stereotypes and translation in advertising

Considerable attention has been dedicated to the study of gender stereotypes in the field of advertising and marketing. Stereotypes refer to the reduction of an individual's identity to a few traits, exaggerating and simplifying them to the extent that no change or development can be done (Antoniou \& Akrivos, 2020). An example is the stereotype of Chinese people as conservative whereas American people are open-minded. Thus, male stereotypes are beliefs that certain traits are specific for men. For example, men are assertive. These stereotypical portrayals have been frequently adopted by advertisers and marketers to appeal to their intended audience (Eisend et al., 2019).

Advertising translators are confronted with the challenge of addressing male-related traits in different markets. Cross-cultural marketing has been recognised as challenging because of the diversity of markets across different nations (McCartan \& McMahon, 2020). Male role expectations are deeply rooted in culture, with culture further defined as the "shared belief, attitudes, and behaviors associated with a large and distinct group of people" (p.13). Hofstede's Masculinity (MAS) (Hofstede et al., 2010) is an empirical-based model 
illustrating a complete theory of cultural difference that is applicable for the field of marketing and advertising (An \& Kim, 2007). It is one of the cultural dimensions of the Hofstede model. The other four dimensions include individualism, power distance, uncertain avoidance and long-term orientation, as exemplified by the cultural dimension between China and the US (Table 1). According to McCartan and McMahon (2020), research on the cross-cultural comparisons of gender portrayals can be conducted in countries with a diverse MAS index. However, the countries with various Individualism (IDV) indexes can also be explored regarding their male portrayals. As stated by De Mooij (2018), certain collocations of dimensions have an essential implication for persuasive advertising appeal. Male-related traits in this context are argued to be persuasive messages for the intended customers. For instance, the IDV index will reflect personality traits (e.g., assertive vs. self-possessed). Therefore, the male portrayals between China and the US could be explained by the Hofstede model because these countries have a relatively large difference in their IDV indexes, with 20 and 91 , respectively.

Table 1: Hofstede et al.'s (2010) Cultural Dimensions Between China and the US.

\begin{tabular}{lll}
\hline Cultural Dimensions & China & US \\
\hline Individualism Index (IDV) & 20 & 91 \\
\hline Power Distance (PDI) & 80 & 40 \\
\hline Uncertainty Avoidance Index (UAI) & 30 & 46 \\
\hline Masculinity Index (MAS) & 66 & 62 \\
\hline Long-term Orientation (LTO) & 87 & 26 \\
\hline
\end{tabular}

A review of literature revealed that it contains only scattered references to the interaction between translation and gender stereotypes in advertising texts. For example, Nardi (2011) explored the translation of gender stereotypes in her analysis of automobile adverts in Italian and British culture. The part of male stereotypes in her study refers to the 'maleness' of cars, such as power, speed and performance. From the text style aspect, Chulanova and Shevchenko (2017) studied gender-marked words in advertising texts. In their study, the male stereotypes relate to units denoting a certain style of text (e.g., neutral), even rude language for the male audience. These studies examined the interplay between male stereotypes and translation either from the visual interpretation or language style of advertising texts. However, the translation of male-related traits to suggest the interplay between translation and male stereotypes remains a neglected area of research.

\section{Transcreation Strategies}

As the name suggests, transcreation involves translation and creation, which means adapting existing advertising material for different markets and creating new texts (C. Pedersen, 2015). Scholars have argued that transcreation is within translation, with translation used in its broad sense. Many scholars have contended that all translation strategies apply to transcreation. For instance, Gaballo (2012) argued that all possible strategies could be adopted in transcreation and that four aspects are required for transcreation, including fluency (the ability to produce ideas and relevant responses), flexibility (the ability to reorient views), originality (the ability to generate unique and new ideas) and elaboration (the ability to grow ideas). Similar to Gaballo (2012), D. Pedersen(2014, 2016) stated that this "overall theoretical framing of translation" (p.68) might be suitable when describing transcreation strategies, such as target-oriented strategies, Nida's dynamic equivalence and the functionalist 
approach. Based on the findings of these studies, it is predicted that all translation strategies could apply to transcreation to achieve desired persuasive effects.

When accounting for the choice of transcreation strategies, the cultural aspects of advertising should also be considered. As stated by Munday (2004), "the unit of translation is not just text, but the culture" (p.209). Given that advertising texts are rooted in a different culture, the target audience has different expectations towards certain products or brands. For instance, Gromová et al. (2017) examined the intercultural aspect in translating advertising texts in American, German and Slovak. The study results raised the awareness that intercultural differences play an important role in the choices of translation strategies.

Various scholars have proposed several taxonomies of translation strategies regarding cultural aspects (Katan, 2014; Liddicoat, 2015; Morón \& Calvo, 2018; J. Pedersen, 2011). To explain, Katan (2014) identified the meta-model as comprising translation strategies, including generalisation, deletion and distortion. Liddicoat (2015) advanced Katan's metamodel by further explaining three strategies of text distortion, namely expansion, replacement and reframing. Moreover, translation strategies under domestication and foreignisation can be applied to translating cultural factors. J. Pedersen (2011) categorised translation strategies in terms of the degree of intervention. Marked intervention strategies include omission, generalisation, substitution and specification while minimum change involves retention, official equivalent and direct translation. This taxonomy is for the rendering of cultural elements (in subtitles). The strength of this taxonomy lies in it being based on an empirical process and mainly semantic operations, making it more appropriate to explain cultural elements involved in translation. However, an overlapping area exists between retention, official equivalent and direct translation. Given the transcreation trend in international advertising involves translation and new content creation (Martin, 2019), translation in this context is understood in its traditional sense as minimal change. Thus, direct translation alone can be used to refer to minimal change. Morón and Calvo (2018) also usefully proposed marked interventional strategies such as omission, addition and modification in their training programme to train their students with professional skills and services for transcreation. A comparison of these taxonomies reveals that substitution is more specific than modification because it specifies the method of modification. Given that creative writing is at the core of transcreation and translation is in its traditional sense when it comes to transcreation, J. Pedersen's (2011) and Morón and Calvo's (2018) categorisations could be combined as the transcreation strategy. The minimal change is direct translation while interventional strategies involve addition, substitution and omission.

\section{Problem Statement}

Advertisers frequently adopt male roles in their advertising campaigns to promote products or build brand images. Such adoption strengthens male stereotypes, which tend to become a norm in modern societies (Montés, 2019). However, unfavourable outcomes occur if men conform to masculine norms. These adverse effects were illustrated by Wong et al. (2017), who conducted a meta-analysis of 78 samples and nearly 20,000 participants. They concluded that conformity to masculine norms impairs male mental health, resulting in depression and loneliness. Specific male stereotypes in adverts can also be exported into the target culture through translation (Montés, 2019). Note that cultural differences exist when rendering malerelated traits. If these differences are not identified and translated appropriately, then the desired persuasive effects in the advertising campaigns will not be achieved. As argued by 
McCartan \& McMahon (2020), when the male portrayals are consistent with the expectation of male customers, the advertising appeals will be more effective.

Previous studies addressing male stereotypes emphasised the content analysis of audio-visual elements of adverts, such as television (Del Saz-Rubio, 2019), magazines (Waling et al., 2018), and Facebook fan pages (Pitaloka \& Suryandaru, 2020). Eisend (2010) stated that personality traits have been seldom researched as they were not directly observed in content analysis. Similarly, Marcon et al. (2019) studied image coding schemes and concluded that most studies concentrated on the content analysis of role behaviours. These studies examined male stereotypes by content analysis of their audio-visual elements. However, research on male stereotypes that examine male-related traits in online verbal advertising texts has been a neglected area. Online verbal advertising texts may promote intended customers to make purchase decisions. Thus, male stereotypes in online verbal advertising texts can be explored through a thematic analysis of male-related traits.

To date, few studies have addressed whether translation or new content creation predominates in the transcreation of male-related traits and the underlying cultural reasons for the strategies adopted. Gender roles evolve at different speeds in different cultures (Eisend, 2019). Different countries respond differently to gender stereotypes in adverts (De Meulenaer et al., 2017; Eisend, 2019). As gender is mostly examined in a binary concept in marketing (Eisend, 2019), it applies to male roles and stereotypes. Thus, advertisers and marketers should consider the cultural aspects of their transcreation practice. To sum up, the objective of this study can be divided into the following research tasks: (1) to identify malerelated traits in English online fragrance labels and their Chinese translations and (2) to identify transcreation strategies adopted to render male-related traits from English online fragrance labels into Chinese and the underlying cultural reasons for such adoption.

\section{Methodology}

This study adopts a qualitative research method that is descriptive and interpretive to examine the translation process and the underlying cultural reasons. In this study, the samples are textual data gathered from American and Chinese fragrance websites.

\section{Inclusion Criteria}

We selected samples from the global top 20 list of fragrance brands in 2020 according to Ranker Community (2019) from September to October 2020. The brands included Chanel, Gucci, Christian Dior, Versace, Bvlgari, Prada and Guerlain. The selection of these widely known brands around the globe was justified because their adverts may be more influential and effective both in China and the US. Among them, brands such as Tom Ford and Creed Boutique were ruled out because only the official American websites were accessible in the given period while no corresponding Chinese official website was found. For those brands that have not been introduced to China yet during the given period of data collection, such as the product named Dolce Vita (eau de toilette) under Christian Dior, they were also not included. Furthermore, limiting the period of data collection to one month ensured that no significant updates were made during such a limited time.

We adopted a non-probability purposive sampling method to select the online labels with male-related traits. The purpose was justified on the basis of the research objectives of the study. The inclusion criteria were as follows. Firstly, the chosen products were under men's fragrance. In the fragrance brands, fragrance was distinctively categorised by gender as the male universe and the female universe. Secondly, online labels, including male-related 
traits of intended customers in both the ST and TT, were selected. For example, online labels include male-related traits such as 'masculine' and 'warm' as well as their derivations and synonyms. Of note, such male-related traits were included either in the ST or TT. Altogether, there were 72 English online fragrance labels and their Chinese equivalents in 10 brands, including Chanel, Gucci, Christian Dior, Bvlgari, Versace, Hermès, Calvin Klein, Burberry, Guerlain and Ralph Lauren.

All the selected fragrance products were captured from websites as a full-size screenshot PNG format, converted into PDF format and then stored. The collected online fragrance labels, both English texts and their Chinese versions, mainly include the following parts: (a) product name, (b) product description, (c) benefits, (d) formula and (e) application tips. Of note, not all brands included all the above parts in their online labels as each brand has its distinctive style.

\section{Data Analysis}

Thematic analysis was used to analyse the data according to the objectives of the study. Firstly, we formulated an instrument to identify male-related traits in online fragrance labels. We combined an adapted version of the 30-Item Bem Sex-Role Inventory (BSRI) (Geldenhuys \& Bosch, 2019) and a classification male-related words (Crawford et al., 2004) to develop our instrument. BSRI is a foundational self-assessment tool of masculinity and femininity, widely used and updated in recent years. It has been used as an evaluation instrument to examine the portrayal of gender characteristics in textbooks (Evans \& Davies, 2000). The evaluation instrument includes eight male-related traits: dominant, assertive, independent, selfpossessed, sensible, masculine, risk-taking and rebellious. The instrument was refined later by adding warmth and sensuality, as these are frequently displayed in online fragrance labels as the ideal traits of intended male customers. Thus, our evaluation instrument has an updated list of 10 male-related traits. We developed working definitions for each trait by drawing on definitions in Merriam-Webster(n.d.) (online dictionary) and considering what they meant in our society (Table 2 ).

Table 2: Definition of male-related traits used in online fragrance labels

\begin{tabular}{|c|c|}
\hline Masculine Traits & Definition \\
\hline dominant & can control and influence situations \\
\hline assertive & can accomplish tasks and handle situations alone with confidence \\
\hline risk-taking & not afraid of taking risks and making difficult decisions \\
\hline self-possessed & $\begin{array}{l}\text { calm, confident and in control of your feelings, even in difficult or unexpected } \\
\text { situations }\end{array}$ \\
\hline masculine & having qualities considered to be typical of men, such as muscular and strong \\
\hline rebellious & deliberately not obeying rules of behaviour \\
\hline sensible & reasonable, practical and showing good judgement \\
\hline energetic & having a lot of energy or determination \\
\hline warm & friendly or making someone feel comfortable and relaxed \\
\hline sexual & relating to the physical activity of sex \\
\hline
\end{tabular}

We likewise combined J. Pedersen's (2011) and Morón and Calvo's (2018) taxonomies as transcreation strategies with minimal and marked intervention strategies. The minimal change includes direct translation, which is a translation strategy when no semantic change is made. The marked interventional strategies include the following: (1) Addition is a 
translation strategy when cultural elements are added in the TT but not provided in the ST. (2) Substitution is a translation strategy when the cultural elements in the ST are something completely different from those in the TT. (3) Omission is a translation strategy when the cultural elements in the ST are not present in the TT. The combined taxonomy is more comprehensive and easier to apply, with broad yet economic categories. With reference to Merriam-Webster (n.d.) (online dictionary), the back translation of male-related traits in Chinese online fragrance labels is presented.

\section{Findings}

Identification of Male-Related Traits

Drawing on Merriam-Webster (n.d.) (online dictionary), we identified 208 pairs of malerelated traits in the online fragrance labels from American and Chinese websites according to the formulated instrument. Out of 72 English online fragrance labels, 53\% male-related traits are sexual and masculine. In comparison, out of 72 Chinese online fragrance labels, $36 \%$ malerelated traits are sexual and masculine. A higher percentage of male-related traits in the English online fragrance labels are sexual and masculine compared to those in their Chinese counterparts. From that perspective, portrayals in the US were found to be slightly more stereotyping than in China.

Identification of Transcreation Strategies

We analysed these male-related traits for their transcreation strategies employed (Table 3), with reference to Merriam-Webster (n.d.) (online dictionary). A total of 120 (57.70\%) of the translation strategies were marked intervention, and 88 (42.30\%) were marked as minimum intervention, showing a relative difference between the two strategies. The most adopted translation strategy of marked interventional strategy is addition, with 46 covering $22.12 \%$ of the total translation strategies. By contrast, the most and only employed translation strategy of minimum intervention is direct translation, with 88 covering $42.30 \%$ of the entire translation strategies.

Table 3: Percentages of Interventional Strategies

\begin{tabular}{|c|c|c|c|c|c|}
\hline \multirow{2}{*}{$\begin{array}{l}\text { Intervention } \\
\text { strategies }\end{array}$} & \multirow[t]{2}{*}{ Strategies } & \multirow{2}{*}{$\begin{array}{l}\text { Number } \\
\text { (No.) }\end{array}$} & \multirow{2}{*}{$\begin{array}{l}\text { Percentage } \\
\text { (\%) }\end{array}$} & \multicolumn{2}{|c|}{ Total } \\
\hline & & & & No. & $\%$ \\
\hline \multirow{3}{*}{ Marked intervention } & Addition & 46 & $22.12 \%$ & \multirow{3}{*}{120} & \multirow{3}{*}{$57.70 \%$} \\
\hline & Substitution & 26 & $12.50 \%$ & & \\
\hline & Omission & 48 & $23.08 \%$ & & \\
\hline Minimum intervention & $\begin{array}{l}\text { Direct } \\
\text { translation }\end{array}$ & 88 & $42.30 \%$ & 88 & $42.30 \%$ \\
\hline
\end{tabular}

The statistics indicate that the creation of male-related traits in the TT was in the majority. The results are consistent with the previous study results that the creation of content is at the core of transcreation (Ho, 2020). According to the Hofstede model, the following section explores the cultural differences between China and the US that underlie marked interventional strategies. As the minimum interventional strategy of direct translation does not involve significant cultural differences, its underlying cultural reasons are not discussed in this paper. 
Marked Interventional Strategies for Male-related traits

Addition is a translation strategy that has been mostly adopted under the marked interventional strategy. There are two situations when addition is needed. One is when general male-related traits are specified to particular ones, as shown in Example 1. Another is when no male-related traits are identified in the ST but found in the TT, as shown in Example 2.

Example 1

ST: To create Sauvage, I used man as my starting point. A strong and unmistakable masculinity. Like the image of a man who transcends time and fashion.

$\mathrm{TT}$ : 狂野男士淡香水以男士的率真锋芒为灵感, 展现别致的阳刚气概. 㴋酒不羁, 传承经典与风尚.

Back translation: Sauvage au de toilette has drawn inspiration from the forthrightness, sincerity and talent of men, unfolding unique masculinity--free-spirited and rebellious characteristics and inheriting classics and fashion.

According to the evaluation instrument of male-related traits, man and strong and unmistakable masculinity in the ST were identified with the male-related trait masculine (Table 4). Note that unmistakable in this context means distinctive according to MerriamWebster (n.d.) (online dictionary), which does not have any specific reference to free-spirited and rebellious characteristics.

Table 4: Example of adding specified traits

\begin{tabular}{ll}
\hline ST & TT \\
\hline man & forthrightness, sincerity and talent of men \\
a strong and unmistakable masculinity & free-spirited and rebellious masculinity \\
\hline
\end{tabular}

According to the Hofstede model, brands in individualist cultures such as the US tend to use abstract personality traits for products. By contrast, concrete traits are added to collectivist cultures such as China, as people in collectivist cultures are more interested in context and situation than in conceptual thinking (De Mooij \& Hofstede, 2010). Thus, in this advertising context, translators transcreate by adding specified traits when translating malerelated traits from individualist cultures to collectivist cultures.

Example 2

ST: ...To refill, twist open the spray to expose the atomizer. Pull up on the atomizer to remove the empty refill canister and replace it with a new one. Gently press the canister into the case and twist the top down to close.

TT：...低调简约的风格...演绎感官享受的愉悦氛围...展现深遂雅致气息. 蔚蓝男士 香水系列诠释了桀謷不驯, 永不妥协的男士鬼力，以独立，坚毅的自由灵魂，书写生命每 一瞬间的篇章.

Back translation: With an understated and simple style...interpreting the atmosphere of sensual pleasures...revealing the feel of profoundness and elegance. BLEU DE CHANEL series interprets the masculine charm of unruliness, persistence, independence, determination and freedom. 
According to the instrument formulated for male-related traits, no male-related traits were identified in the ST while several male-related traits were added to the TT (Table 5). Male-related traits such as sensible, unruliness and self-possessed are identified in the TT with reference to Merriam-Webster (n.d.) (online dictionary). These traits indicate modernisation and the traditional beliefs of men rooted in Confucianism (Zayer et al., 2019). Thus, translators deal with male-related traits based on the traditional Confucius notion of the Chinese to meet the intended Chinese customers' expectations of ideal men.

Table 5: Addition of Male-related Traits

\begin{tabular}{|c|c|c|c|}
\hline ST & TT & Back Translation & Male-related Traits \\
\hline- & 神秘深遄shenmi shensui & mysterious and profound & self-possessed \\
\hline- & 桀謷不驯jieao buxun & unruliness & rebellious \\
\hline- & 独立坚毅duli jianyi & $\begin{array}{l}\text { independence } \\
\text { determination }\end{array}$ & assertive \\
\hline- & 感官享受ganguan xiangshou & sensual pleasures & sexual \\
\hline
\end{tabular}

Substitution is one of the important translation strategies of marked intervention. One male-related trait was substituted with others (Table 6). By substitution, translators use appropriate male-related traits in the target culture to indicate male stereotypes, thus appealing to the intended Chinese customers. According to the Hofstede individualism dimension, China and the US have diverse indexes, with 20 and 91, respectively. The malerelated traits reflected in both cultures are also markedly different.

Traditional culture and its contemporary development in the ST and TT should be considered in the transcreation of male-related traits. For instance, vulnerable was substituted for 温暖wennuan (warm). Vulnerable describes someone who is easily hurt according to Merriam-Webster (n.d.) (online dictionary), which in this context is related to men's sensitivity. In the original English fragrance labels, both virile and vulnerable were used to depict a mythological giant. As a hero, the giant is real when he possesses some weaknesses of ordinary people. However, being vulnerable or sensitive may not be heroic in China because of the influence of the Confucius notion that stresses 翩翩君子Pianpian junzi (perfect gentlemen). 暖男nuannan (warm men), a network buzzword describing gentlemen who are thoughtful, family-oriented and caring for partners and friends, has been quite popular in China in recent years (Li, 2017). It relates to the substituted word 温暖wennuan (warm). Similarly, refined was substituted for 深遂 shensui (deep and profound). With reference to Merriam-Webster (n.d.) (online dictionary), the former describes polite and welleducated men, who are considered to be of high social class. Meanwhile, the latter represents men who show excellent knowledge and perceptions, a typical Confucian trait of ideal men in China. 
Table 6: Examples of substitution

\begin{tabular}{llll}
\hline ST & TT & Back Translation & Male-related Traits \\
\hline vulnerable & 温暖wennuan & warm & warm \\
sexy & 感性ganxing & sensibility & sexual \\
refined & 深遂shensui & deep and profound & self-possessed \\
the male body & 男士的阳刚气魄 nanshi de & masculine spirit & masculine \\
& yanggang qipo & & \\
& & & \\
\hline
\end{tabular}

Owing to the profound impact of Confucianism over thousands of years, Chinese people tend to be comparatively more conservative on sex issues than people in Western countries, including the US (Xu et al., 2019). This accounts for the substitution of sexy by 感 性ganxing (sensibility). Drawing on Merriam-Webster (n.d.) (online dictionary), the former describes sexually attractive men while the latter is a more common and conservative adjective describing responsiveness towards something emotional. Such conservatism also explains why the male body was substituted by the masculine spirit, with the former being visible and the latter invisible. The male body indicates the sensual effect of the fragrance advertised. By contrast, the masculine spirit suggests the spiritual effect of the fragrance advertised.

The motives behind omitting these male-related traits may be that they cannot arouse the same emotional response in the target culture. Americans are being led by sexually explicit media, while China is conservative about the topic of sex (Ruan, 1991/2013). Thus, translators chose to delete such suggestive words as sexy and provocative in advertising in the TT (Table 7).

Table 7: Examples of omission

\begin{tabular}{|l|l|l|}
\hline ST & TT & Male-related Traits \\
\hline sexy & - & sexual \\
\hline eloquent & - & sensible \\
\hline provocative & - & sexual \\
\hline defy convention & - & rebellious \\
\hline strong personality & - & dominant \\
\hline
\end{tabular}

Advertisers may resort to male-related traits from the perspective of historical culture. For instance, the concept of eloquence in the Western countries can be traced back to the ancient Greeks. It spreads across the European and American colonies since the 18th century as a tool for political philosophers and revolutionaries to distribute the notion of freedom and liberty. Besides, defy convention is an expression that means rebellious or unruly according to Merriam-Webster (n.d.) (online dictionary). The US has a history of revolting against England and builds the US. Thus, being unruly is part of the American personality. When translated into Chinese, both eloquent and defy convention have been omitted in the webadverts as China does not have such historical culture. The same reason accounts for the translation of strong personality. Such words or expressions expressing individualism indicate the historical culture in the US. If directly translated into Chinese web-adverts, it could not get the same persuasive effect.

To sum up, a combination of J. Pedersen's (2011) and Morón and Calvo's (2018) taxonomies could be used to identify the transcreation strategies in online fragrance labels. 
Adopting this combined taxonomy, this study describes the transference of male-related traits from English into Chinese, thus providing implication for the interplay between transcreation and male stereotypes in advertising. Marked interventional strategies and minimal change under this combined taxonomy indicate the predominance of creation of new content in transcreation. Moreover, the Hofstede model could be used to explain the cultural differences between China and the US, when taking account of MAS and IDV dimensions.

\section{Discussion}

We began our study by attempting to identify male-related traits in online fragrance labels to investigate how male stereotypes were rendered through transcreation and the underlying cultural reasons for the strategies adopted. Our investigation revealed a series of important findings. First, males in the ST and TT were depicted with traits such as sensual and masculine. The suggestive or sexualised portrayals of ideal men in both texts confirm the trend concluded by scholars such as Paek et al. (2011) and Dafferner at al. (2019). Such depiction is likewise consistent with the notion of commodified masculinity concluded by scholars such as Waling et al. (2018) and hegemonic masculinity by Del Saz-Rubio (2019). Furthermore, the male portrayals were found to be more stereotypical in the English online fragrance labels than in the Chinese ones, which is consistent with the views held by scholars such as Xu et al. (2019). The comparisons of male stereotypes in advertising between China and the US add to the literature on East-West comparison of male portrayals.

In addition, marked interventional strategies prevail over minimal interventional strategies in the transcreation strategies of male-related traits. This reflects the cultural differences of masculinity between China and the US. With regard to the transcreation strategies of male-related traits in online fragrance labels, three main situations of transcreation are involved as follows. (1) Omission: there are male-related traits in the ST but not in the TT. (2) Addition: there are male-related traits in the TT but not in the ST. (3) Substitution: there are male-related traits in both the ST and TT, but they refer to different traits. This finding further confirms the notion of transcreation, that is, transcreation involves translation and the creation of new content (C. Pedersen, 2015), and the creation of new content is at the core of transcreation as stated by scholars such as Ho (2020). It supplemented transcreation approaches by identifying marked and minimum interventional strategies, with marked interventional strategies prevailing over minimal change. In other words, the creation of new content prevails over translation, with translation used in its traditional sense. Besides, the cultural reasons underlying the transcreation of male-related traits have been explained. Cultural elements, such as male stereotypes, are argued to contribute greatly to transcreation in this study. In comparison, Nardi (2011) argued that transcreation plays an important role in transmitting cultural elements such as male stereotypes. These two views are opposite sides of the same coin: the interplay between transcreation and male stereotypes.

Another important finding of the present study is that Hofstede's MAS dimension could not be used alone to explain differences in male portrayals across cultures, confirming the view of Koinig et al. (2020) that MAS dimension could not be used to explain differences in gender portrayals cross-culturally. Although China and the US have a relatively small difference in MAS index, with 66 and 62, respectively, differences in male-related traits are still observed and could be explained. The study results confirmed the idea by De Mooij (2018), supplementing that a combination of Hofstede's IDV dimension and MAS dimension provides an implication regarding male stereotyping across cultures. 
This study should be viewed, like all studies, with limitations. Firstly, the products and brands selected in this article cannot be considered to be exhaustive. Secondly, stereotypical male portrayals were only examined from the perspective of male-related traits. Future research is needed for identifying the transcreation strategies used for female-related traits in online fragrance labels to see if there are any differences between male-related traits and female ones. Likewise, the online labels of other products such as cosmetic and automobiles can be explored.

\section{Acknowledgments}

The authors are immensely grateful to Dr. Uma Rani A Rethina Velu and Dr. Aida Azlina Mohd Bee for their valuable comments and constructive suggestions on earlier versions of the manuscript.

\section{References}

An, D., \& Kim, S. (2007). Relating Hofstede's masculinity dimension to gender role portrayals in advertising: A cross-cultural comparison of web advertisements. International Marketing Review, 24(2), 181-207. https://doi.org/10.1108/02651330710741811

Antoniou, A., \& Akrivos, D. (2020). Gender portrayals in advertising: stereotypes, inclusive marketing and regulation. Journal of Media Law, 12(1), 78-115. https://doi.org/10.1080/17577632.2020.1783125

Chulanova, G. V., \& Shevchenko, S. V. (2017). Gender marker words in advertising texts: The equivalence of translation. Філологічні Tрактатu[Philological Treatises], 9(4), 109115. https://doi.org/http://nbuv.gov.ua/UJRN/Filtr_2017_9_4_18

Crawford, J. T., Leynes, P. A., Mayhorn, C. B., \& Bink, M. L. (2004). Champagne, beer, or coffee? A corpus of gender-related and neutral words. Behavior Research Methods, Instruments, \& Computers, 36(3), 444-458.

Dafferner, M., Campagna, J., \& Rodgers, R. F. (2019). Making gains: Hypermuscularity and objectification of male and female Olympic athletes in sports illustrated across 60 years. Body Image, 29,156-160. https://doi.org/10.1016/j.bodyim.2019.04.001

De Meulenaer, S., Dens, N., De Pelsmacker, P., \& Eisend, M. (2017). How consumers' values influence responses to male and female gender role stereotyping in advertising. International Journal of Advertising, 37(6), 893-913. https://doi.org/10.1080/02650487.2017.1354657

De Mooij, M. (2018). Global marketing and advertising: Understanding cultural paradoxes (5th ed.). SAGE Publications, Inc.

De Mooij, M., \& Hofstede, G. (2010). The Hofstede model: Applications to global branding and advertising strategy and research. International Journal of Advertising, 29(1), 85110. https://doi.org/10.2501/S026504870920104X

Deaux, K., \& Lewis, L. L. (1984). Structure of gender stereotypes: Interrelationships among components and gender label. Journal of personality and Social Psychology, 46(5), 9911004.

Del Saz-Rubio, M. M. (2019). The pragmatic-semiotic construction of male identities in contemporary advertising of male grooming products. Discourse and Communication, 13(2), 192-227. https://doi.org/10.1177/1750481318817621

Eisend, M. (2010). A meta-analysis of gender roles in advertising. Journal of the Academy of Marketing Science, 38(4), 418-440. https://doi.org/10.1007/s11747-009-0181-x

Eisend, M. (2019). Gender roles. Journal of Advertising, 48(1), 72-80. 
https://doi.org/10.1080/00913367.2019.1566103

Eisend, M., Dens, N., \& De Pelsmacker, P. (2019). Gender roles in advertising. In S. Rodgers \& E. Thorson (Eds.), Advertising theory (2th ed., pp. 187-197). Taylor \& Francis.

Evans, L., \& Davies, K. (2000). No Sissy Boys Here: A Content Analysis of the Representation of Masculinity in Elementary School Reading Textbooks. Sex Roles, 42(3-4), 255-270. https://doi.org/10.1023/A:1007043323906

Gromová, E., Müglová, D., \& Perez, E. (2017). Culture in advertising and advertising in culture: Communication, translation, representation. Ars Aeterna, 9(2), 81-92. https://doi.org/10.1515/aa-2017-0011

Gaballo, V. (2012). Exploring the boundaries of transcreation in specialized translation. ESP Across Cultures, 9, 95-113. http://www.edipuglia.it/volume.php?id=733

Geldenhuys, M., \& Bosch, A. (2019). A Rasch Adapted Version of the 30-Item Bem Sex Role Inventory (BSRI). Journal of Personality Assessment, 102(3), 428-439. https://doi.org/10.1080/00223891.2018.1527343

Ho, N. M. (2020). Transcreation in marketing: a corpus-based study of persuasion in optional shifts from English to Chinese. Perspectives: Studies in Translation Theory and Practice, 1-13. https://doi.org/10.1080/0907676X.2020.1778046

Hofstede, G., Hofstede, G. J., \& Minkov, M. (2010). Cultures and organizations: Software of the mind: Intercultural cooperation and its importance for survival (3rd ed.). McGrawHill.

Katan, D. (2014). Translating cultures: An introduction translators, interpreters and mediators. Routledge.

Koinig, I., Diehl, S., \& Terlutter, R. (2020). Gender-role portrayals in advertising: State of the art and cross-cultural differences. In The international encyclopedia of gender, media, and communication (pp. 1-7). Wiley Online Library. https://doi.org/10.1002/9781119429128.iegmc198

Li, Y. (2017). 新媒体语境下新兴性别称谓语研究[Study on the emerging address terms in the context of new media]语言教学与研究第四期(总第186期)[Language Teaching and Linguistic Studies, 186(4)], 97-103.

Liddicoat, A. J. (2015). Intercultural mediation, intercultural communication and translation. Perspectives: Studies in Translatology, 24(3), 354-364. https://doi.org/10.1080/0907676X.2014.980279

Luo, J. (2019). Niche perfumes: China's growing appetite for unusual fragrances. Luxury Society. Retrieved December 22, 2020 from, https://www.luxurysociety.com/en/articles/2019/02/niche-perfumes-chinas-growingappetite-unusual-fragrances/

Marcon, F. A., Petroll, M. de L. M., Barros, L. B. L., \& Rocha, R. A. da. (2019). Female stereotypes in advertising - A systematic review of literature. Brazilian Journal of Marketing Research, Opinion and Media, 12(3), 236-258.

Martin, E. (2019). Global marketing translation and localization for French-speaking countries. World Englishes, 38(3), 366-386. https://doi.org/10.1111/weng.12429

McCartan, A., \& McMahon, F. (2020). Gender and advertising. In The International Encyclopedia of Gender, Media, and Communication (pp. 1-17). Wiley Online Library. https://doi.org/10.1002/9781119429128.iegmc068

Merriam-Webster. (n.d.). Retrieved December 22, 2020, from https://www.merriamwebster.com/dictionary/ 
Montés, A. (2019). Teaching gender issues in advertising translation: The case of University marketing. In M. De Marco \& P. Toto (Eds.), Gender approaches in the translation classroom (pp. 63-82). Palgrave Macmillan, Cham.

Morón, M., \& Calvo, E. (2018). Introducing transcreation skills in translator training contexts: A situated project-based approach. Journal of Specialised Translation, 29, 126-148.

Munday, J. (2004). Advertising: some challenges to translation theory. The Translator, 10(2), 199-219. https://doi.org/10.1080/13556509.2004.10799177

Nardi, V. (2011). Translation in advertising: Marketing cars in Italy and the UK since the 1980s[unpublished doctoral dissertation]. The University of Warwick.

Paek, H. J., Nelson, M. R., \& Vilela, A. M. (2011). Examination of gender-role portrayals in television advertising across seven countries. Sex Roles, 64(3-4), 192-207. doi:10.1007/s11199-010-9850-y

Pedersen, C. (2015). Exploring the concept of transcreation: A theoretical and empirical study of transcreation with BMW as an empirical example [Doctoral dissertation. Aarhus University]. http://pure. au. dk/portal/files/61306039/Thesis. pdf

Pedersen, D. (2014). Exploring the concept of transcreation-transcreation as "more than translation".Cultus: The Journal of Intercultural Mediation and Communication, 7, 5771.

Pedersen, D. (2016). Transcreation in marketing and advertising: an ethnographic study [Doctoral dissertation, Aarhua University].

https://pure.au.dk/portal/files/99715430/Transcreation_in_Marketing_and_Advertisin g_An_Ethnographic_Study1.pdf

Pedersen, J. (2011). Subtitling norms for television: An exploration focusing on Extralinguistic Cultural References. John Benjamins Publishing Company.

Pitaloka, Y. A., \& Suryandaru, Y. S. (2020). Male representation in beauty clinic advertisements. Talent Development and Excellence, 12(2s), 313-318.

Ranker Community. (2019, September 12). The Best Perfumers and Fragrance Makers. https://www.ranker.com/crowdranked-list/best-perfumers-and-fragrancemakers?ref=search

Rovai, S. (2018). Digitalisation, luxury fashion and "Chineseness": The influence of the Chinese context for luxury brands and the online luxury consumers experience. Journal of Global Fashion Marketing, 9(2), 116-128. https://doi.org/10.1080/20932685.2018.1435294

Ruan, F. F. (2013). Sex in China: Studies in sexology in Chinese culture. Springer Science \& Business Media.(Original work published in 1991)

Waling, A., Duncan, D., Angelides, S., \& Dowsett, G. W. (2018). Men and masculinity in men's magazines: A review. Sociology Compass, 12(7), 1-26. https://doi.org/10.1111/soc4.12593

Wong, Y. J., Ho, M.-H. R., Wang, S.-Y., \& Miller, I. S. K. (2017). Meta-analyses of the relationship between conformity to masculine norms and mental health-related outcomes. Journal of Counseling Psychology, 64(1), 80-93.

https://psycnet.apa.org/doi/10.1037/cou0000176

Xu, H., Zhang, Z., Wu, L., \& Wang, C. J. (2019). The Cinderella complex: Word embeddings reveal gender stereotypes in movies and books. PLOS ONE, 14(11), 1-18. https://doi.org/10.1371/journal.pone.0225385

Zayer, L. T., McGrath, M. A., \& Castro-González, P. (2019). Men and masculinities in a changing world: (de)legitimizing gender ideals in advertising. European Journal of Marketing, 54(1), 238-260. https://doi.org/10.1108/EJM-07-2018-0502 